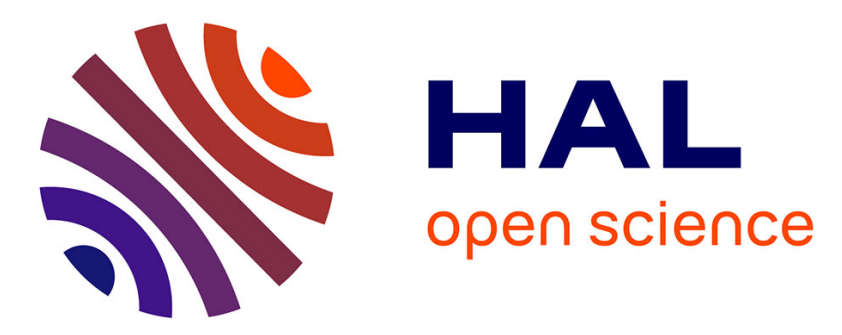

\title{
Analysis and fate of 14 relevant wastewater-derived organic pollutants in long-term exposed soil
}

Nicola Montemurro, Cristina Postigo, Serge Chiron, Damià Barceló, Sandra Perez

\section{- To cite this version:}

Nicola Montemurro, Cristina Postigo, Serge Chiron, Damià Barceló, Sandra Perez. Analysis and fate of 14 relevant wastewater-derived organic pollutants in long-term exposed soil. Analytical and Bioanalytical Chemistry, 2019, 411 (12), pp.2687-2696. 10.1007/s00216-019-01715-3 . hal-03142496

\section{HAL Id: hal-03142496 \\ https://hal.umontpellier.fr/hal-03142496}

Submitted on 16 Feb 2021

HAL is a multi-disciplinary open access archive for the deposit and dissemination of scientific research documents, whether they are published or not. The documents may come from teaching and research institutions in France or abroad, or from public or private research centers.
L'archive ouverte pluridisciplinaire HAL, est destinée au dépôt et à la diffusion de documents scientifiques de niveau recherche, publiés ou non, émanant des établissements d'enseignement et de recherche français ou étrangers, des laboratoires publics ou privés. 


\title{
Analysis and fate of 14 relevant wastewater-derived organic pollutants in long-term exposed soil
}

\author{
Nicola Montemurro $^{1} \cdot$ Cristina Postigo $^{1} \cdot$ Serge Chirón ${ }^{2} \cdot$ Damiá Barcelò $^{1} \cdot$ Sandra Pérez $^{1}$ \\ Received: 26 November 2018 / Revised: 17 February 2019 / Accepted: 25 February 2019 \\ (C) Springer-Verlag GmbH Germany, part of Springer Nature 2019
}

\begin{abstract}
The growing use of reclaimed water in agriculture worldwide calls for developing high-sensitivity methods to quantify wastewater-derived organic contaminants in soils so that the potential risk of this irrigation practice can be properly assessed. This work describes an analytical method for the determination of trace levels of 14 drugs that are known to be poorly removed during conventional wastewater treatment in soil. The analytes selected for investigation included ten pharmaceuticals from different therapeutic classes (carbamazepine diclofenac, cis-diltiazem lamotrigine, methadone, midazolam, oxcarbazepine, sulfamethoxazole, trimethoprim, valsartan), one illicit drug (cocaine), and three transformation products/metabolites (acridone, 4'hydroxydiclofenac, and valsartan acid), thereby covering a broad range of physical-chemical properties. The methodology developed was based on ultrasonic solvent extraction (USE) of the analytes from the soil matrix, and subsequent clean-up and analysis of the USE extracts with a fully automated approach by means of solid-phase extraction and liquid chromatographytandem mass spectrometry detection (online SPE-LC-MS/MS). The method was fully validated with affording method detection and quantification limits ranging from 0.03 to $1 \mathrm{ng} \mathrm{g}^{-1}$ and from 0.09 to $3.3 \mathrm{ng} \mathrm{g}^{-1}$, respectively. This method was applied to investigate the fate of the selected drugs in potting soil irrigated for a long term (60 days) either with water containing the target compounds at a concentration of $200 \mu \mathrm{g} \mathrm{L}{ }^{-1}$ or with wastewater treatment plant effluent and thus, at real environmental concentrations. All investigated compounds were found to accumulate in soil irrigated with artificially fortified water. The highest accumulation potential was observed for cis-diltiazem followed by methadone and midazolam that presented average concentrations of $1517 \mathrm{ng} \mathrm{g}^{-1}, 1041 \mathrm{ng} \mathrm{g}^{-1}$, and $962 \mathrm{ng} \mathrm{g}^{-1}$ d.w., respectively. On the contrary, oxcarbazepine $\left(5.8 \mathrm{ng} \mathrm{g}^{-1}\right)$ and sulfamethoxazole $\left(22 \mathrm{ng} \mathrm{g}^{-1}\right)$ were the target drugs presenting the lowest accumulation potential. Only trace levels of ten drugs were measured in soil irrigated with regenerated water (average concentrations between 1.6 and $4.7 \mathrm{ng} \mathrm{g}^{-1}$ d.w.).
\end{abstract}

Keywords Pharmaceuticals - Soil adsorption - Ultrasound extraction · Online solid-phase extraction · Liquid chromatography-mass spectrometry $\cdot$ Reclaimed water

\section{Introduction}

For many decades, soil contamination by heavy metals, pesticides, and persistent organic pollutants has raised concern. With the rapid economic development, and the increasing use of highly diverse chemicals for industrial, agricultural, and domestic purposes, the spectrum of the compounds being released into the environment has radically changed. It includes now a variety of biologically active compounds, like pharmaceuticals and illicit drugs. As a result, soils are also exposed to this new and emerging threat [1]. The growing concern about pharmaceuticals being released into soils is reflected in the increasing number of published studies that explore their fate in this environmental compartment and the potential effects associated. Pharmaceuticals can enter into the terrestrial environment by either solid waste 
disposal or agricultural application of organic waste products that may contain trace levels of these substances, like manure, wastewater treatment plant effluents, and sewage sludge [2-16]. Certain antibiotics were found to persist after manure storage and application on agricultural fields, and consequently, they could eventually leach into groundwater [17]. Once released, these contaminants, despite being polar and ionizable, could also persist in the soil matrix for long periods and, consequently, adversely affect microbes, worms, and other soil organisms [1]. Furthermore, their presence can contribute to the selection and proliferation of antibiotic-resistant bacteria [18-20]. Any pharmaceutical accumulated in soil could also potentially be uptaken by growing crops, which represents a potential risk to human health [4, 21-27]. In this regard, carbamazepine (CBZ), one of the drugs most frequently detected in soils [5], has been reported to translocate from soil to plant tissues [21].

Concentrations of pharmaceutically active compounds in soils are usually relatively low (in the low $\mathrm{ng} \mathrm{g}^{-1}$ level), presenting values below those commonly reported in water [5, 28]. Such low levels and the potential interactions of these substances with active soil sites make their extraction and detection in this matrix a real analytical challenge.

Several approaches have been used to extract these relatively polar compounds from soil, e.g., pressurized liquid extraction (PLE), microwave-assisted extraction (MAE), pressurized hot water extraction (PHWE), ultrasonic solvent extraction (USE), and QuEChERS (Quick, Easy, Cheap, Effective, Rugged and Safe) [29-38]. USE has been proved to be one of the most efficient techniques for the extraction of polar compounds from environmental solid samples [38]. It also has the benefit of being a relatively quick method that does not require sophisticated equipment.

USE extracts need to be cleaned-up before liquid chromatography-mass spectrometry (LC-MS) analysis to remove co-extracted salts and humic and fulvic acids, main constituents of soil organic matter, that could otherwise interfere in the ionization of the target analytes [39]. For this, solidphase extraction (SPE) has been widely used. This process can be automated and coupled to the detection system (online SPE), thereby reducing lab effort, sample handling, and analysis time and, consequently, improving method reproducibility and increasing sample throughput.

In this context, the aim of this study was to evaluate the effectiveness of USE followed by an online SPE clean-up approach coupled in series with the LC-MS detection system (online SPE-LC-MS/MS) for the analysis of selected wastewater-derived organic pollutants in soil. Fourteen compounds, covering a wide range of physical-chemical properties, were considered. The list of selected chemicals included diclofenac (anti-inflammatory/analgesic), the antibiotics sulfamethoxazole and trimethoprim, the antiepileptics carbamazepine, oxcarbazepine, and lamotrigine, the anti-hypertensives cis-diltiazem and valsartan, the tranquilizer midazolam (benzodiazepine), and the analgesic methadone (opioid-agonist). In addition, one illicit drug (cocaine) and three transformation products (TPs) (acridone, 4'-hydroxydiclofenac, and valsartan acid) were included. Method development and performance have been presented and discussed. As part of the validation process, the methodology was applied to the analysis of the selected drugs in potting soil samples irrigated either with a mixture of these pollutants $\left(200 \mu \mathrm{g} \mathrm{L}^{-1}\right)$ or with treated wastewater (environmental concentrations) for 60 days with the final aim of evaluating their long-term accumulation potential.

\section{Materials and methods}

\section{Chemicals}

Certified reference standards used for method development and analytical purposes (Table S1, see Electronic Supplementary Material, ESM) were of high purity (mostly 99\%) and were purchased from Sigma-Aldrich (St. Luis, MO, USA) and Cerilliant (Round Rock, TX, USA). Isotopelabeled compounds (carbamazepine- $\mathrm{d}_{10}$, cocaine- $\mathrm{d}_{5}$, diclofenac- $d_{4}$, lamotrigine- ${ }^{13} \mathrm{C}_{3}$, methadone- $\mathrm{d}_{3}$, midazolam- ${ }^{13} \mathrm{C}_{6}$, sulfamethoxazole- $\mathrm{d}_{4}$, trimethoprim- $\mathrm{d}_{3}$, valsartan- $\mathrm{d}_{3}$, valsartan acid- $\mathrm{d}_{4}$ ) were purchased from Cerilliant, Alsachim (Illkirch-Graffenstaden, France), or Toronto Research Chemicals (Toronto, ON, Canada) for their use as surrogate standards. In view of the high amounts of analytical standards needed for the soil irrigation experiments and the high price of some of them, marketed drug products were purchased, i.e., midazolam (EFG injectable solution, $5 \mathrm{mg} \mathrm{mL}{ }^{-1}$, Normon, Madrid, Spain), valsartan (Valsartan 40 mg, Kern Pharma S.L., Barcelona, Spain), oxcarbazepine (Trileptal® 300 mg, Novartis, Switzerland). Cocaine hydrochloride salt and methadone hydrochloride salt were provided for research purposes (2009C00124) by the Division of Narcotic Drugs and Psychotropic Substances of the Spanish Agency of Pharmaceuticals and Medical products. Valsartan acid ( $\geq 95 \%$ ) was synthesized and purified following the procedure described by Nödler et al. [40].

LC-MS grade acetonitrile $(\mathrm{ACN})(\geq 99.9 \%)$, methanol $(\mathrm{MeOH})(\geq 99.9 \%)$, and water were purchased from Merck (Darmstadt, Germany). Dimethyl sulfoxide (DMSO) $(\geq$ $99 \%)$ and formic acid ( $\geq 96 \%$, ACS reagent) were supplied by Sigma-Aldrich. Polytetrafluoroethylene (PTFE) filters (13 $\mathrm{mm}, 0.2 \mu \mathrm{m}$ ) were purchased from Millipore (Carrigtwohill, Cork, Ireland). Oasis HLB online SPE cartridges $(10 \times 1 \mathrm{~mm}, 30-\mu \mathrm{m}$ particle size, $2.5 \mathrm{mg})$ were supplied by Waters Corporation (Milford, MA, USA).

Individual reference standard stock solutions $\left(1000 \mu \mathrm{g} \mathrm{mL}^{-1}\right)$ were prepared in $\mathrm{MeOH}$ except lamotrigine which was prepared in DMSO. Working mixtures of 
pharmaceuticals and/or surrogate standards $\left(2 \mu \mathrm{g} \mathrm{mL}^{-1}\right)$, used in the validation studies and for calibration purposes, were prepared by diluting an appropriate volume of the stock solutions in $\mathrm{MeOH}$. All solutions were stored in the dark at $20{ }^{\circ} \mathrm{C}$. A dechlorinated tap water-based standard mixture $\left(200 \mu \mathrm{g} \mathrm{L}^{-1}\right)$ [21] of the target analytes was freshly prepared before each watering event.

\section{Soil characterization and experimental setup}

Commercially available sterile potting soil was purchased from a local organic garden store (Barcelona, Spain). This type of soil was selected because it has a soft consistency and good organic fertilization, and it is representative of a well ventilated and well-balanced natural soil. Furthermore, the sterilization treatment ensured that seeds of weeds that could interfere with the experiment did not sprout. Physicalchemical characterization of this soil, i.e., total nitrogen Kjeldahl (TNK), available phosphorus $\left(\mathrm{P}_{2} \mathrm{O}_{5}\right)$, exchangeable potassium $\left(\mathrm{K}_{2} \mathrm{O}\right)$, sodium $\left(\mathrm{Na}^{+}\right)$, magnesium $\left(\mathrm{Mg}^{2+}\right)$, calcium $\left(\mathrm{Ca}^{2+}\right)$, and organic matter (O.M.) content, was conducted according to the Italian Official Methods of Soil Chemical Analysis [41]. For this, an aliquot of soil was air-dried for 5 days, crushed, and sieved (mesh size $2 \mathrm{~mm}$ ) before analysis. Electrical conductivity (EC) and $\mathrm{pH}$ were determined by potentiometry in a soil sample dispersed in distilled water, using a soil:water ratio (by weight) of 1:2.5 and 1:2, respectively. Soil characteristics are presented as ESM in Table S2. This soil was used for method optimization and validation as well as in the experiment conducted to evaluate the potential accumulation of the target drugs. For the latter, nine plastic flowerpots of $20-\mathrm{cm}$ diameter were filled with $2000 \pm 5 \mathrm{~g}$ of potting soil. Three pots were used as experiment controls (irrigated with dechlorinated tap water), three other pots were irrigated with dechlorinated water fortified with the analyte mixture $\left(200 \mu \mathrm{g} \mathrm{L}^{-1}\right)$, and the remaining three were irrigated with wastewater treatment plant effluent. All pots were placed in a greenhouse and were daily watered with $100 \mathrm{~mL}$ of the corresponding water for 60 days.

\section{Soil sample collection and extraction}

Before sample collection at the end of the irrigation period, the pots were not irrigated for 2 days and the content of each pot was well homogenized. A sample aliquot of approximately $100 \mathrm{~g}$ was taken from each pot and stored at $-20^{\circ} \mathrm{C}$. The samples were freeze-dried (LyoAlfa 6, Telstar Technologies, Terrassa, Spain) and then finely ground using a mortar and passed through $400-\mu \mathrm{m}$ and $250-\mu \mathrm{m}$ sieves to remove gravel, sand, and other coarse particles. Freeze-dried samples were kept at $-20^{\circ} \mathrm{C}$ until extraction.

The extraction approach used was adapted from a methodology previously developed by the authors to analyze the target compounds in lettuce [21]. For soil analysis, a freezedried soil aliquot $(0.5 \mathrm{~g})$ was weighed into a $50-\mathrm{mL}$ centrifuge tube and fortified with a known amount of the surrogate standard mixture (100 $\mathrm{ng} \mathrm{g}^{-1}$ ). Then, the soil aliquot was left for $1 \mathrm{~h}$ in the fume hood to allow $\mathrm{MeOH}$ evaporation, and stored afterward at $4{ }^{\circ} \mathrm{C}$ overnight. Before extraction, $2 \mathrm{~mL}$ of $0.1 \%$ formic acid HPLC-grade water solution was added. The sample was then vortex-shaken for $30 \mathrm{~s}$ and left to soak for $2 \mathrm{~h}$ at room temperature, to promote the interaction of the acidic water with the soil matrix. Subsequently, $16 \mathrm{~mL}$ of ACN:MeOH $(1: 1, v / v)$ was added, and the sample was vortexed for $60 \mathrm{~s}$ and sonicated for $20 \mathrm{~min}$ (Fisherbrand FB15064 ultrasonic water bath; Fisher Scientific, Pittsburgh, PA, USA). Upon sonication time, the sample was centrifuged at $4000 \mathrm{rpm}$ for $15 \mathrm{~min}$, and the supernatant was transferred to a $60-\mathrm{mL}$ glass vial. The extraction procedure was then repeated once again using the same extracting solvent and conducted a third time using $16 \mathrm{~mL}$ of $0.5 \%$ formic acid in ACN:MeOH $(1: 1, v / v)$. All three supernatants collected were combined and evaporated to $2 \mathrm{~mL}$ under a gentle stream of nitrogen at $24{ }^{\circ} \mathrm{C}$ using a TurboVap ${ }^{\circ}$ LV (Biotage AB, Uppsala, Sweden). After evaporation, the extracts were redissolved in $100 \mathrm{~mL}$ of HPLC-grade water and filtered through a $0.2-\mu \mathrm{m}$ PTFE syringe filter. The filtrate was transferred to a $10 \mathrm{~mL}$-vial for clean-up and analysis by means of online SPE-LC-MS/MS.

\section{Sample clean-up and analysis}

Soil extracts were cleaned-up and analyzed using an automated online SPE sample processor Symbiosis ${ }^{\mathrm{TM}}$ Pico (Spark Holland) connected in series with a 4000QTRAP hybrid triple quadrupole-linear ion trap (QqLIT) mass spectrometer (Sciex, Redwood City, CA, USA). For clean-up, $5 \mathrm{~mL}$ of the aqueous extract was loaded at a low flow rate $\left(1 \mathrm{~mL} \mathrm{~min}{ }^{-1}\right)$ onto a previously conditioned Oasis HLB cartridge $(2 \mathrm{~mL}$ of ACN and $2 \mathrm{~mL}$ of $\mathrm{MeOH}$ and equilibrated with $2 \mathrm{~mL}$ of water at a flow rate of $5 \mathrm{~mL} \mathrm{~min}^{-1}$ ). Upon extract loading, the cartridge was washed with $1 \mathrm{~mL}$ of HPLC water to complete sample transfer and remove matrix interferences such as inorganic salts. Retained analytes were then eluted from the cartridge with the LC mobile phase (linear organic gradient of acetonitrile in water with formic acid, see Table S3 in ESM) and transferred to the LC column (Purospher STAR RP-18 endcapped column $(125 \times 2 \mathrm{~mm}$ i.d., 5 - $\mu \mathrm{m}$ particle size, Merck, Darmstadt, Germany)). Ionization of the analytes was done using a Turbo Ion Spray source operated in positive electrospray ionization mode (ESI+). MS acquisition was performed in the selective reaction monitoring (SRM) mode, by acquiring two SRM transitions per target analyte and one for the corresponding surrogate compound. A detailed description of the optimization of the LC-MS/MS conditions selected has been provided elsewhere [21]. The SRM transitions 
monitored for each analyte are summarized alongside with the optimal instrumental conditions set for their analysis in Table 1.

\section{Method validation}

The optimized method was validated in terms of linearity, recovery, intra-day precision, limits of detection (MDLs) and quantitation (MQLs), and matrix effects.

The linearity of the method was evaluated in a matrixmatched calibration curve constructed between 0.5 and $1000 \mathrm{ng} \mathrm{g}^{-1} \mathrm{~d} . \mathrm{w}$. (equivalent to $0.0025 \mathrm{ng} \mathrm{mL}^{-1}$ and $5 \mathrm{ng} \mathrm{mL}^{-1}$, respectively, in the aqueous extract). Calibration curves were constructed using linear weighted least-squares regression ( $1 / \mathrm{x}$ as weighting factor) by plotting the ratio of the analyte signal to that of its corresponding surrogate standard (added at a fix concentration of $100 \mathrm{ng} \mathrm{g}^{-1}$ d.w $\left(0.5 \mathrm{ng} \mathrm{mL}^{-1}\right)$ in all samples) as a function of the analyte and surrogate standard concentrations ratio. Surrogate standards used in each case are shown in Table 1.

The accuracy of the method was evaluated through analyte recovery. For this, soil samples $(n=3)$ were fortified with the fourteen target compounds before USE at two concentration levels (50 $\mathrm{ng} \mathrm{g}^{-1}$ and $400 \mathrm{ng} \mathrm{g}^{-1}$ d.w.) and analyzed. Background concentrations of target analytes in the soil sample used for the recovery study were also evaluated and considered in the calculation of analyte recoveries.

Recoveries of the extraction procedure (RE) [42] were determined by comparing the response (peak area) for analytes spiked before extraction and online clean-up $\left(\mathrm{A}_{\text {spiked-soil }}\right)$ with the corresponding peak areas for standards spiked after the extraction ( $\mathrm{A}_{\text {spiked-matrix }}$ ) at equivalent concentrations (50 $\mathrm{ng} \mathrm{g}^{-1}$ and $400 \mathrm{ng} \mathrm{g}^{-1}$ d.w.) according to Eq. 1:

$$
R E(\%)=100 *\left(\frac{A_{\text {spiked-soil }}}{A_{\text {spiked-matrix }}}\right)
$$

Method repeatability (intra-day precision) was assessed by the relative standard deviation (RSD) of the relative recoveries obtained after analysis of soil samples $(n=3)$ fortified at two levels (50 $\mathrm{ng} \mathrm{g}^{-1}$ and $400 \mathrm{ng} \mathrm{g}^{-1}$ d.w.).

Method detection limits (MDLs) and method quantification limits (MQLs) were determined as the minimum detectable amount of analyte with a signal-to-noise ratio $(\mathrm{S} / \mathrm{N})$ of 3 and 10 , respectively. They were calculated using the $\mathrm{S} / \mathrm{N}$ ratio observed in the soil samples fortified at the lowest level (50 ng g ${ }^{-1}$ d.w.).

The assessment of the presence of matrix effects (ME) was based on direct comparison of the analytes' response (peak areas) obtained after online SPE-LC-MS/MS analysis of (.) soil samples $(n=3)$ fortified with the analyte mixture at

t1.1 Table 1 Conditions used for the LC-ESI(+)-MS/MS analysis of the target analytes

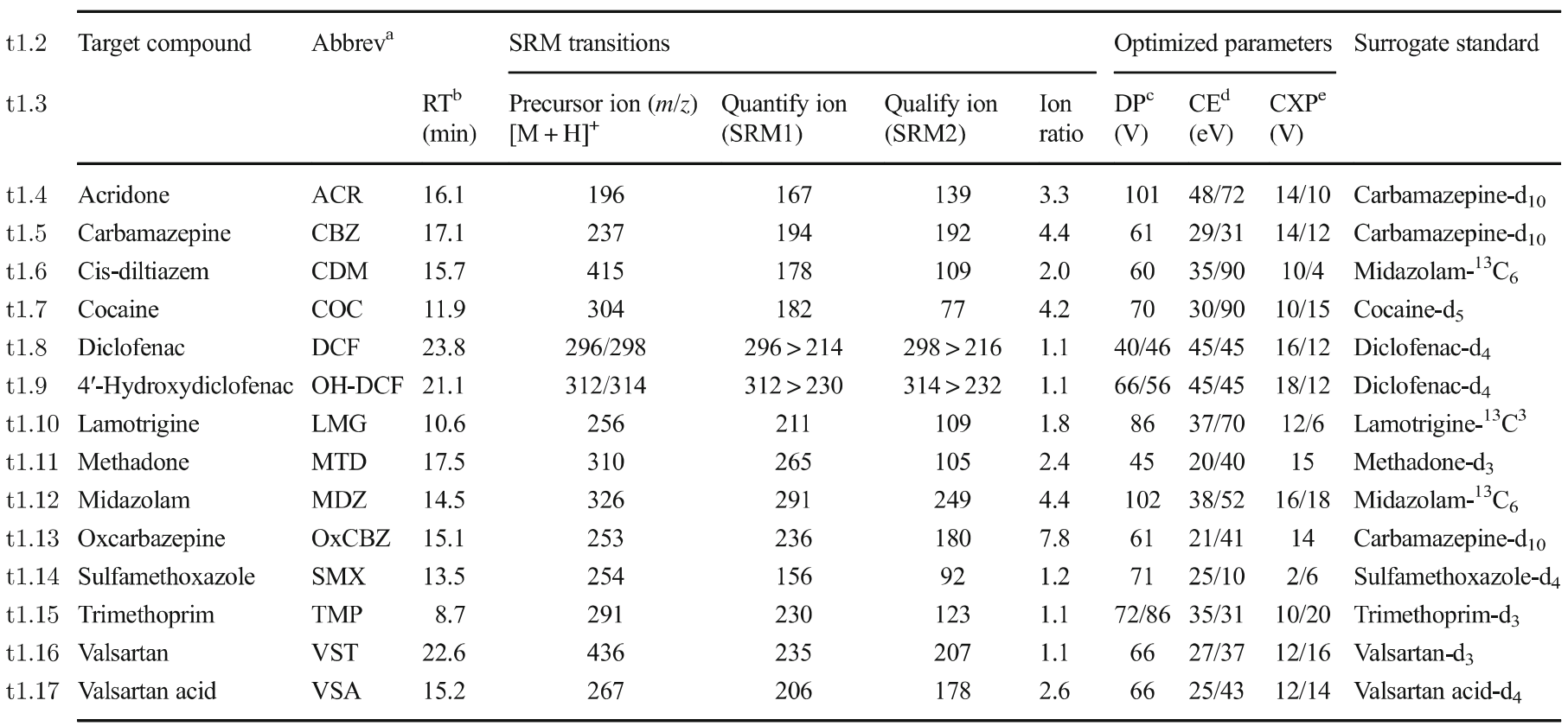

\footnotetext{
${ }^{\text {a }}$ Abbreviation

${ }^{\mathrm{b}}$ Retention time

${ }^{\mathrm{c}}$ Declustering potential

${ }^{\mathrm{d}}$ Collision energy

${ }^{\mathrm{e}}$ Collision cell exit potential
} 
Analysis and fate of 14 relevant wastewater-derived organic pollutants in long-term exposed soil

$50 \mathrm{ng} \mathrm{g}^{-1}$ and $400 \mathrm{ng} \mathrm{g}^{-1} \mathrm{~d} . \mathrm{w}$ after USE extraction $\left(\mathrm{A}_{\text {spiked- }}\right.$ matrix $)$ and HPLC-grade water fortified at equivalent concentrations $\left(0.25 \mathrm{ng} \mathrm{mL}^{-1}\right.$ and $2 \mathrm{ng} \mathrm{mL}^{-1}$, respectively) (A $\left.\mathrm{A}_{\mathrm{HPC}}\right)$, according to Eq. 2:

$\mathrm{ME}(\%)=\left(\frac{A_{\text {spiked-matrix }}}{A_{\mathrm{HPLC}}}-1\right) * 100$

\section{Results and discussion}

\section{Soil characterization}

Main physical-chemical characteristics of the soil used for method development and in the irrigation experiments are summarized in Table S2 (ESM). After the irrigation period, $\mathrm{EC}$ and $\mathrm{pH}$ of the soil slightly increased, as well as divalent cations $\left(\mathrm{Mg}^{2+}\right.$ and $\left.\mathrm{Ca}^{2+}\right)$ and $\mathrm{P}_{2} \mathrm{O}_{5}$. These changes could originate from the characteristics of the dechlorinated tap water used for irrigation (hard water with high conductivity). In general, an increase in the soil $\mathrm{pH}$ may lead to a reduced availability of microelements, the formation of insoluble phosphates, and the increase of the calcium amount.

\section{Sample extraction}

The extraction method was based on a USE approach. Before USE extraction, the lyophilized soil sample was rehydrated to favor analyte desorption from soil particles, because water molecules compete with the analytes for the adsorption sites of the soil humic substances. This process also allows the organic solvents to interact better with the pores of the soil $[36,43]$.

The ACN:MeOH $(1: 1, v / v)$ extraction solvent was proven to be one of the best options to extract the target compounds from lettuce [21]. Thus, it was also selected to extract the compounds of interest from soil samples. The addition of formic acid ( $0.5 \%$ formic acid in the ACN:MeOH (1:1) solvent mixture) to enhance the extraction efficiency and stabilize the $\mathrm{pH}$ was also evaluated. In fact, the presence of formic acid may contribute to breaking the ionic interactions potentially occurring between ionized pharmaceuticals and the charged surfaces of the soil. Analyte recoveries from soil using the solvent mixture with and without acid are summarized in Fig. 1. As shown in the figure, most of the analytes were better extracted with the non-acidified than with the acidified mixture, except methadone, cis-diltiazem, and cocaine, whose recoveries increased by 74,73 , and $95 \%$, respectively, when the acidified solvent was used. Aiming at keeping the method as simple as possible and similar to our previously reported method [21], and to maximize extraction efficiency for most target compounds, analyte extraction was performed

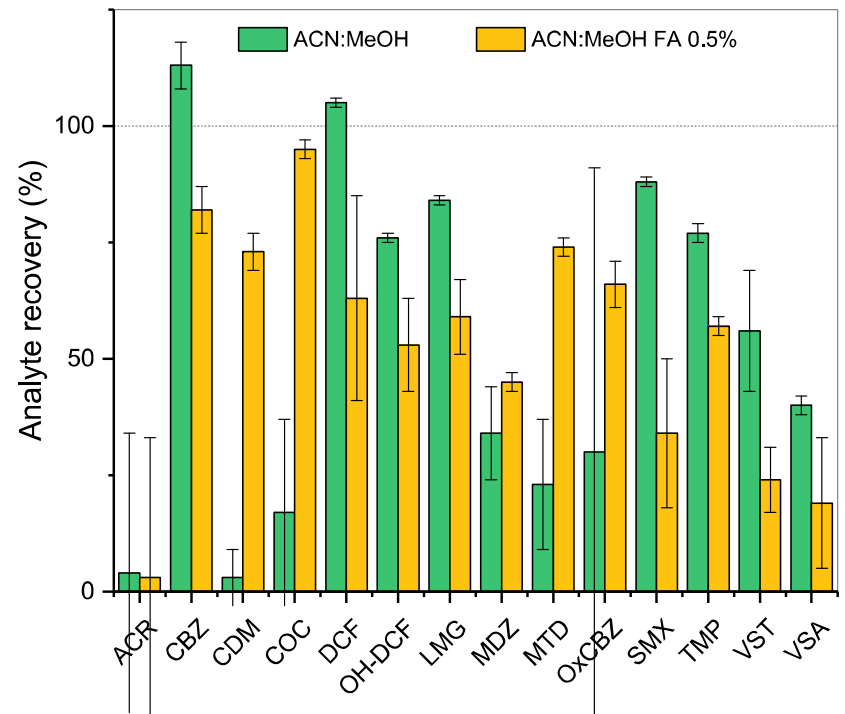

Fig. 1 Effect of acid addition on analyte recovery from a soil sample ( $n=$ 3) fortified at a concentration of $100 \mathrm{ng} \mathrm{g}^{-1}$ d.w

with two USE cycles using ACN:MeOH $(1: 1, v / v)$ and a third one using the acidified solvent mixture.

\section{Extract clean-up and analysis}

Since soil is a highly complex matrix, an SPE-based clean-up step of the USE extracts obtained was evaluated so that matrix components interfering with MS ionization could be reduced, as well as the frequency of cleaning the MS ionization source. Depending on the nature of the sample, matrix components may enhance or suppress the ionization of the analytes, compromising thereby the accuracy of the measurements [44].

For clean-up, and due to the different physical-chemical properties of the target analytes, two generic-purpose sorbents, i.e., Oasis HLB and HySphere Resin GP, were evaluated by extracting HPLC-grade water fortified with the target analytes at a concentration of $100 \mathrm{ng} \mathrm{L}^{-1}$. The retention of the target analytes on the tested sorbents during the clean-up process is showed in Fig. S1 (ESM). The results indicated a satisfactory retention capacity of both sorbents for the target analytes, with recovery values comprised between 45 and $110 \%$ for most of the compounds, except for OH-DCF (120\% with Oasis HLB), SMX (46\% with Oasis HLB and $24 \%$ with HySphere Resin GP, VST (46.5\% with Oasis HLB and $36 \%$ with HySphere Resin GP), and VSA (below $20 \%$ with both sorbents). Oasis HLB was selected over HySphere Resin GP because it provided improved repeatability of the results (RSD $<15 \%$ in general) and a better recovery efficiency for cis-diltiazem, cocaine, methadone, sulfamethoxazole, and valsartan, compounds that were otherwise poorly recovered.

The online SPE-LC-MS/MS analysis of HPLC-grade water right after the online SPE analysis of high-concentration fortified soil samples or calibration solutions in a sequence 
Montemurro N. et al.

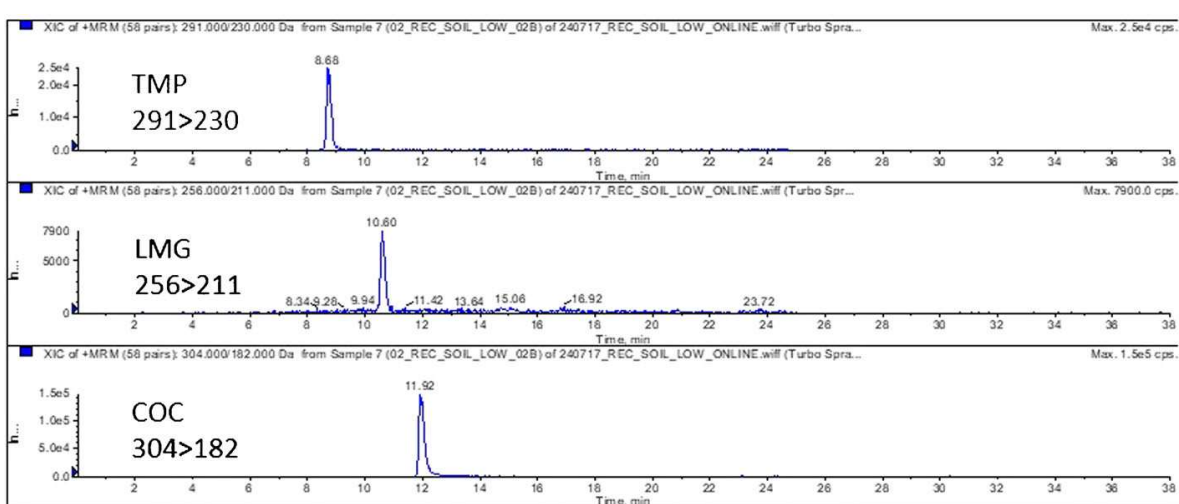

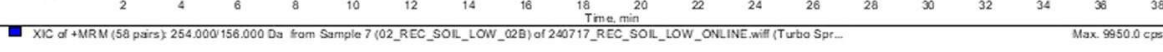

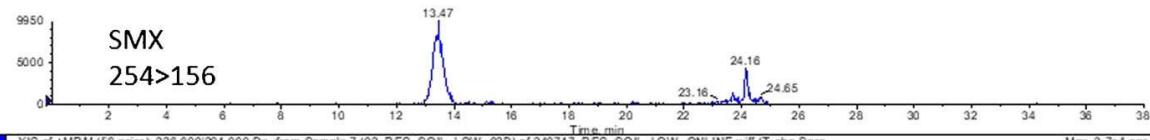

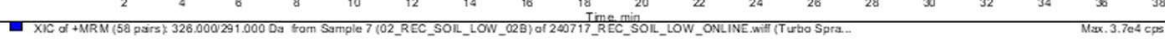

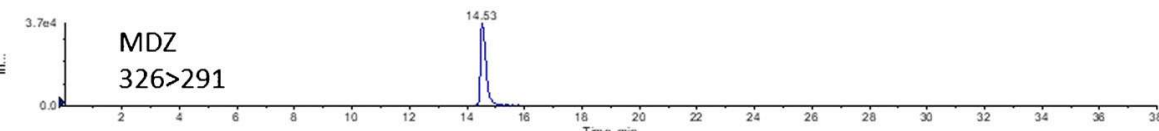

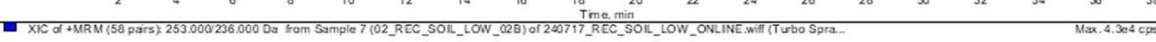

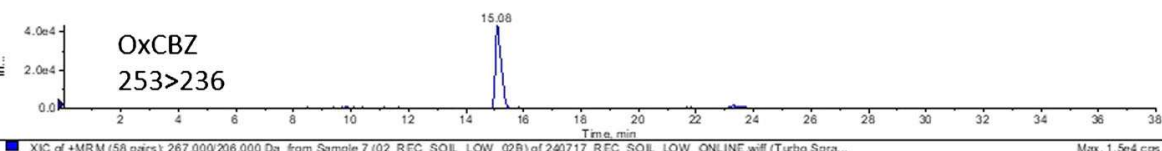

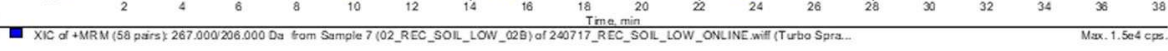

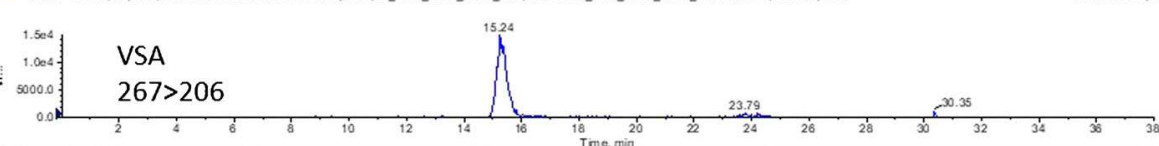

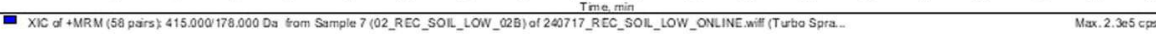

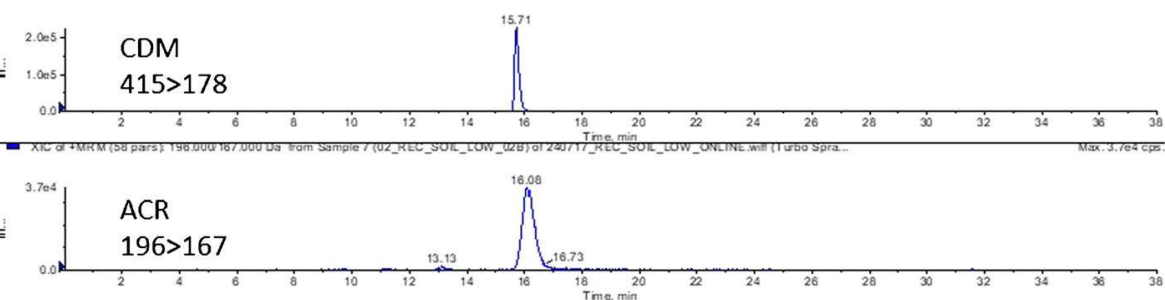

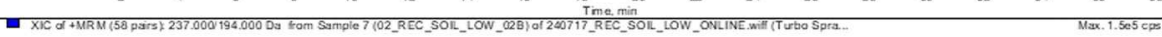

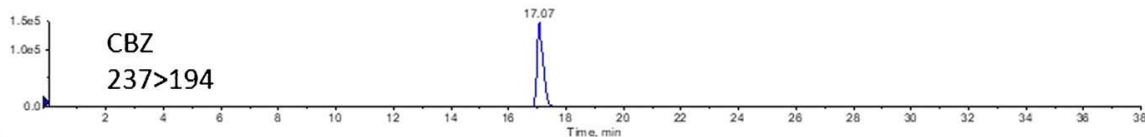

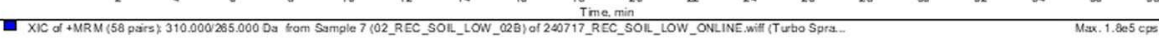

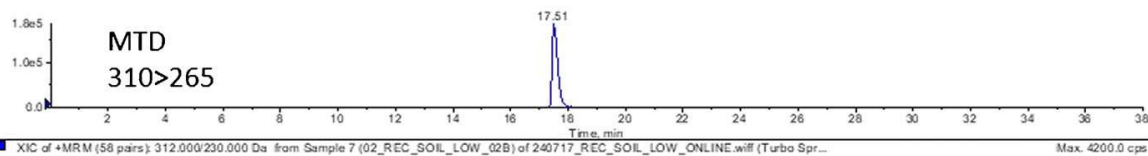

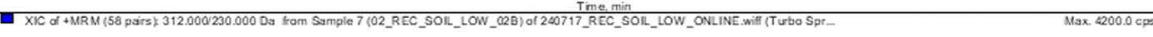

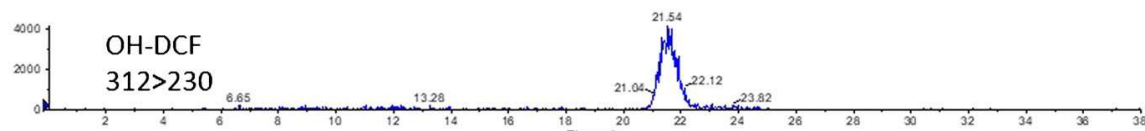

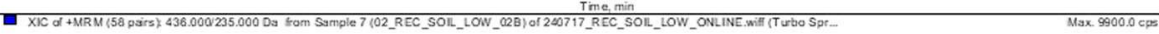

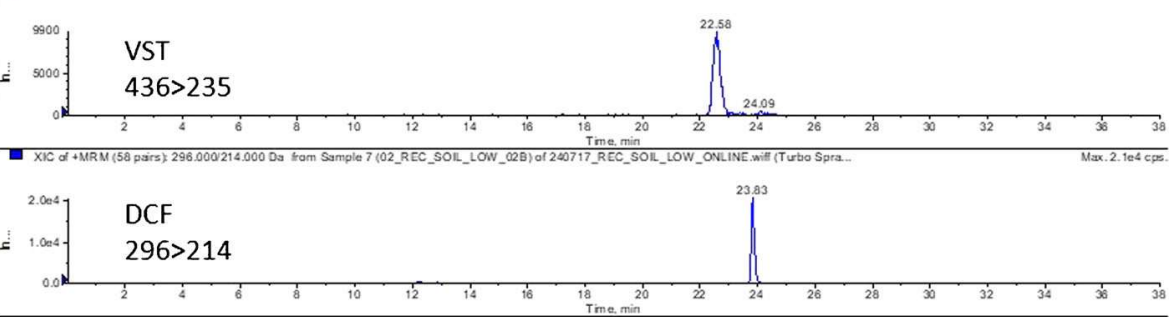


Fig. 2 LC-MS/MS chromatograms of the target analytes obtained in PI mode from a soil extract spiked at a concentration of $50 \mathrm{ng} \mathrm{g}^{-1} \mathrm{~d} . \mathrm{w}$. of each compound and ordered by RT.

confirmed the absence of carry-over or memory effects during the automated SPE procedure.

LC-ESI-MS/MS conditions, summarized in Table 1 and ESM Table S3, were optimized in a previous work [21] for all compounds but for OH-DCF and SMX, which were optimized after direct infusion of individual standard solutions $\left(0.5 \mu \mathrm{g} \mathrm{mL}^{-1}\right)$ into the MS. The analysis of all target analytes in a single analytical run under positive ionization contributes to reducing analysis time and cost, despite the fact that diclofenac, valsartan, and valsartan acid are better ionized in negative than in positive mode. Extracted ion chromatograms (XIC) of the target analytes after USE and online SPE-LCMS/MS analysis of a soil sample fortified at a concentration of $50 \mathrm{ng} \mathrm{g}^{-1}$ d.w. are shown in Fig. 2.

\section{Method performance}

The optimized approach was validated for the analysis of the target compounds in soil samples in terms of linearity, accuracy (analyte recovery), intra-day precision (repeatability), sensitivity, and matrix effects. Method performance has been summarized in Table 2.

Linearity ranges for the different analytes were determined by constructing matrix-matched calibration curves with a minimum of eight calibration points within the concentration range $0.5-1000 \mathrm{ng} \mathrm{g}^{-1}$ (equivalent to $0.0025 \mathrm{ng} \mathrm{mL}^{-1}$ and $5 \mathrm{ng} \mathrm{mL} \mathrm{m}^{-1}$, respectively, in the soil extract). The matrixmatched curves for each compound were built using blank extracts. Linearity expanded between 0.5 or the analyte limit of quantification if higher and $1000 \mathrm{ng} \mathrm{g}^{-1}$ for all compounds, except for cocaine, diclofenac, hydroxydiclofenac, lamotrigine, oxcarbazepine, sulfamethoxazole and trimethoprim, for which the linearity of the response extended only up to $500 \mathrm{ng} \mathrm{g}^{-1}$ (equivalent to $2.5 \mathrm{ng} \mathrm{mL}^{-1}$ ). Calibration curves presented coefficients of determination $\left(R^{2}\right)$ above 0.99 for all compounds. The accuracy of calibration solutions was $\pm 20 \%$ of the corresponding nominal concentrations (up to $\pm 25 \%$ at the lowest concentration).

Recovery values were obtained as the average of triplicate measurements at both spiked levels ( $50 \mathrm{ng} \mathrm{g}^{-1}$ and $400 \mathrm{ng} \mathrm{g}^{-1}$ d.w.). The wide interval was chosen in order to cover a wide range of concentrations since there are no maximum limits or standards recognized by the regulations in force. Results are summarized in Table 2. Recoveries ranged from $78 \%$ (MDZ and VSA) to $114 \%$ (CDM) for the low fortification level and from $71 \%$ (OH-DCF) to $122 \%$ (MTD) at a high level. Relative standard deviations (method repeatability) were below $10 \%$ in all cases, confirming the good performance of the proposed method.
The MDLs and MQLs ranged from 0.03 to $1 \mathrm{ng} \mathrm{g}^{-1}$ and from 0.09 to $3.3 \mathrm{ng} \mathrm{g}^{-1}$ d.w., respectively. For most of the target analytes, MDLs and MQLs achieved were of the same order of magnitude than those reported in previously published methods in soil $[32,45,46]$.

\section{Matrix effects}

Matrix effects, shown in Fig. 3, ranged on average from 37\% (valsartan acid) to $-52 \%$ (diclofenac). As a general trend, suppression was more prominent than enhancement, maybe due to poor specificity of the sorbent or to saturation of the sorbent capacity by co-extracted matrix substances. This high variability of the matrix effects underlined the importance of using isotopically labeled compounds as surrogate standards or matrix-matched calibration curves to ensure the accuracy and reliability of the results. Note that isotopically labeled analogs were not available for the quantification of acridone and oxcarbazepine (see Table 1).

\section{Long-term exposure study}

The proposed method was successfully applied to study the accumulation of the target compounds in potting soil that was irrigated with a solution containing the compounds of interest for 60 days. Furthermore, to verify the suitability of the presented methodology at environmental conditions, another set of soil pots $(n=3)$ was irrigated during the same period with the effluent water from a wastewater treatment plant running with conventional activated sludge treatment. The selection of potting soil as substrate instead of real agricultural soil was made because it provides adequate ventilation, and it has good water absorption before becoming waterlogged or excessively dry [47, 48], and good initial nutrient supply (see ESM Table S2). Therefore, potting soil is ideal to grow plants and vegetables in a controlled environment such as a greenhouse. Positive identification of the analytes in the potting soil samples was performed following the standards set by Directive $2002 / 657 /$ EC on the performance of analytical methods and interpretation of the results [49], by comparing the analyte retention time and SRM ratio (see Table 1) in the sample and in a standard solution.

None of the analytes under investigation was determined neither in the blank soil extract nor in the control pots (irrigated with tap water). On the contrary, all of them were found in all intentionally contaminated soil samples (irrigated with $200 \mu \mathrm{g} \mathrm{L}^{-1}$ of each analyte). Concentrations measured in these soil samples are summarized in Fig. 4a. The most abundant compounds were cis-diltiazem, methadone, and midazolam. For the quantitative determination of the concentrations of these compounds, samples had to be diluted and re-analyzed. Average concentrations of cisdiltiazem, methadone, and midazolam were 1517, 1041, 
t2.1 Table 2 Method performance for the determination of the target analytes in soil samples at two concentration levels (50 and $400 \mathrm{ng} \mathrm{g}^{-1}$ d.w.): linearity range and coefficients of determination $\left(R^{2}\right)$, accuracy (analyte recoveries (RE\%), method repeatability (RSD), and method limits of detection (MDL) and quantification (MQL)

\begin{tabular}{|c|c|c|c|c|c|c|c|c|c|}
\hline \multirow{2}{*}{$\begin{array}{l}\mathrm{t} 2.2 \\
\mathrm{t} 2.3\end{array}$} & & \multicolumn{2}{|l|}{ Linearity } & \multirow{2}{*}{\multicolumn{2}{|c|}{$\begin{array}{l}\text { Analyte recoveries } \\
\text { RE\% }\end{array}$}} & \multirow{2}{*}{\multicolumn{2}{|c|}{$\frac{\text { Repeatability }}{\text { RSD\% }}$}} & \multicolumn{2}{|l|}{ Sensitivity } \\
\hline & & \multirow[t]{2}{*}{ Range (ng g ${ }^{-1}$ ) } & \multirow[t]{2}{*}{$R^{2}$} & & & & & \multirow[t]{2}{*}{$\mathrm{MDL}^{\mathrm{c}}\left(\mathrm{ng} \mathrm{g}^{-1}\right)$} & \multirow[t]{2}{*}{$\mathrm{MQL}^{\mathrm{c}}\left(\mathrm{ng} \mathrm{g}^{-1}\right)$} \\
\hline $\mathrm{t} 2.4$ & & & & $50 \mathrm{ng} \mathrm{g}^{-1}$ & $400 \mathrm{ng} \mathrm{g}^{-1}$ & $50 \mathrm{ng} \mathrm{g}^{-1}$ & $400 \mathrm{ng} \mathrm{g}^{-1}$ & & \\
\hline $\mathrm{t} 2.5$ & Acridone $^{\mathrm{a}}$ & $0.5-1000$ & 0.9996 & 97 & 82 & 0.7 & 3 & 0.3 & 0.9 \\
\hline $\mathrm{t} 2.6$ & Carbamazepine & $1-1000$ & 0.9984 & 99 & 89 & 1.5 & 1.2 & 0.1 & 0.34 \\
\hline $\mathrm{t} 2.7$ & Cis-Diltiazem $^{\mathrm{b}}$ & $0.5-1000$ & 0.9984 & 114 & 100 & 7 & 0.1 & 0.03 & 0.09 \\
\hline $\mathrm{t} 2.8$ & Cocaine & $0.5-500$ & 0.9962 & 105 & 85 & 0.6 & 3 & 0.03 & 0.12 \\
\hline $\mathrm{t} 2.9$ & Diclofenac & $05-500$ & 0.9983 & 86 & 73 & 3 & 2.3 & 0.3 & 1 \\
\hline $\mathrm{t} 2.10$ & 4'-Hydroxydiclofenac & $1-500$ & 0.9989 & 82 & 71 & 1.1 & 1.8 & 0.6 & 2 \\
\hline $\mathrm{t} 2.11$ & Lamotrigine & $5-500$ & 0.9976 & 92 & 78 & 3 & 3 & 1 & 3.3 \\
\hline $\mathrm{t} 2.12$ & Methadone & $0.5-1000$ & 0.9986 & 102 & 122 & 2.6 & 1 & 0.05 & 0.15 \\
\hline $\mathrm{t} 2.13$ & Midazolam & $0.5-1000$ & 0.9996 & 78 & 71 & 2.8 & 1.5 & 0.3 & 0.9 \\
\hline $\mathrm{t} 2.14$ & Oxcarbazepine $^{\mathrm{a}}$ & $0.5-500$ & 0.9994 & 79 & 62 & 1.2 & 0.5 & 0.3 & 1.1 \\
\hline t2.15 & Sulfamethoxazole & $0.5-500$ & 0.9979 & 90 & 84 & 1.5 & 7 & 0.5 & 1.6 \\
\hline $\mathrm{t} 2.16$ & Trimethoprim & $0.5-500$ & 0.9995 & 81 & 76 & 3.8 & 1.2 & 0.2 & 0.8 \\
\hline $\mathrm{t} 2.17$ & Valsartan & $0.5-1000$ & 0.9997 & 93 & 87 & 3.7 & 1.7 & 0.3 & 1.2 \\
\hline $\mathrm{t} 2.18$ & Valsartan acid & $0.5-1000$ & 0.9990 & 78 & 100 & 5.4 & 2.5 & 0.5 & 1.6 \\
\hline
\end{tabular}

${ }^{a}$ Compound quantified with carbamazepine- $\mathrm{d}_{10}$ as surrogate standard

${ }^{\mathrm{b}}$ Compound quantified with midazolam- ${ }^{13} \mathrm{C}_{6}$ as surrogate standard

${ }^{c}$ Estimated from the mass spectrometry signal observed in the real samples or the recovery samples at $50 \mathrm{ng} \mathrm{g}^{-1} \mathrm{~d} . \mathrm{w}$

and $962 \mathrm{ng} \mathrm{g}^{-1}$ d.w., respectively. The lowest potential accumulation was observed for acridone, sulfamethoxazole, valsartan, and valsartan acid that presented average concentrations below $72 \mathrm{ng} \mathrm{g}^{-1}$ d.w. While RSD values of the measured concentrations were low $(<20 \%)$ for

Fig. 3 The extent of matrix effects affecting the USE and LCMS/MS analysis of the target compounds in soil samples acridone, carbamazepine, methadone, and midazolam, high variability of the results was observed for the remaining compounds. This could be attributed to the potential degradation of these compounds in the soil throughout the experiment duration.

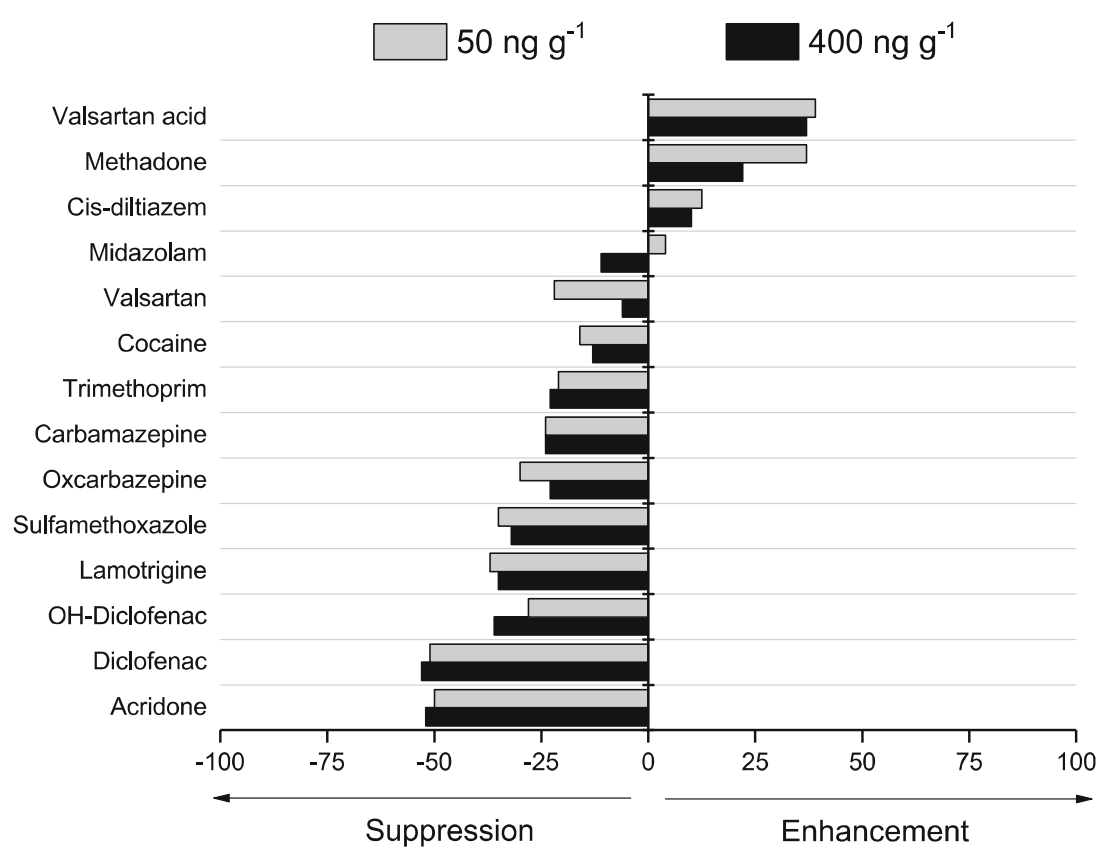


Analysis and fate of 14 relevant wastewater-derived organic pollutants in long-term exposed soil
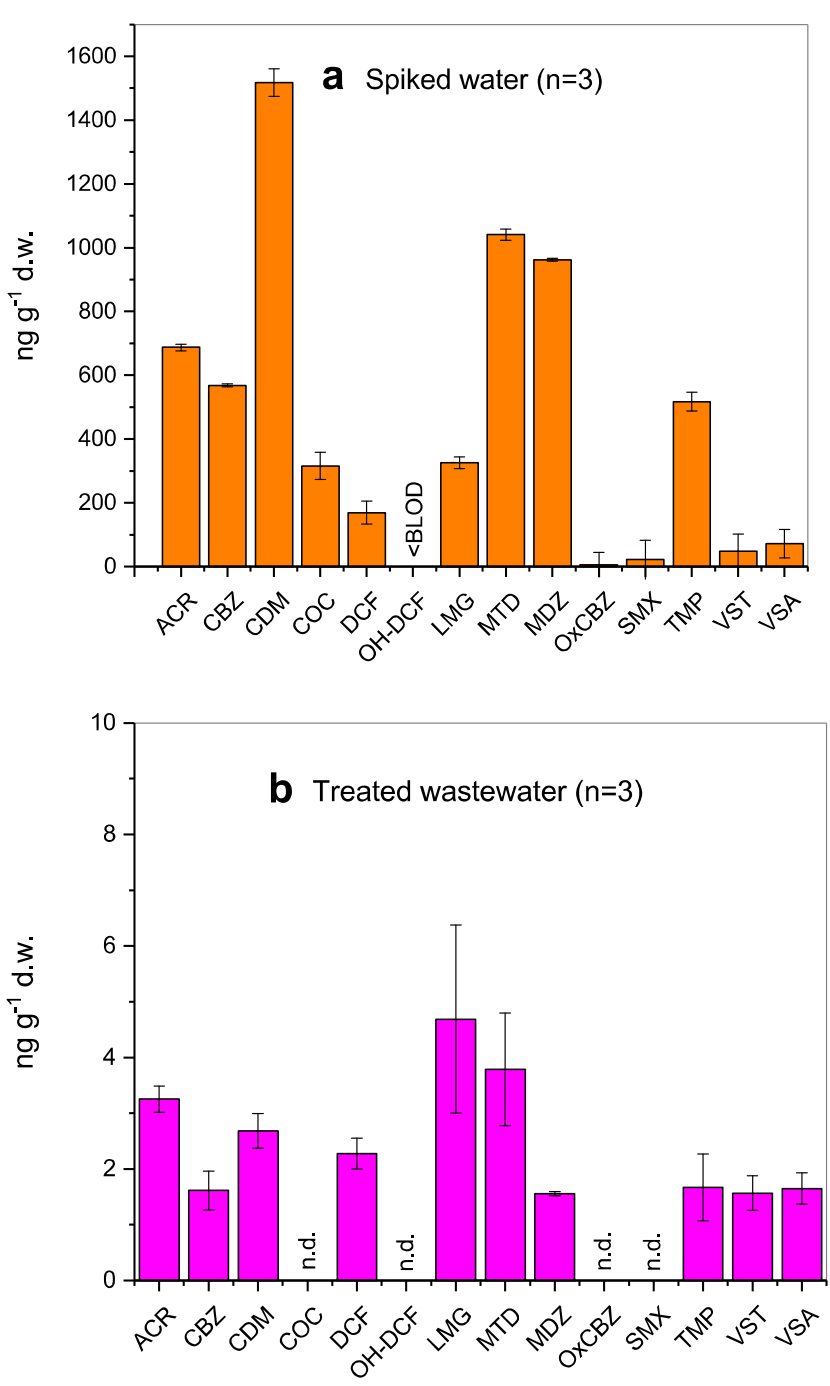

Fig. 4 Average concentration (ng $\mathrm{g}^{-1}$ d.w.) of the target compounds detected in artificially contaminated soil (a) and WWTP-effluent waterirrigated soil (b) $(n=3)$

As for the soils irrigated with wastewater treatment plant effluent, only 10 out of the 14 target compounds were detected. Most of them were measured at average concentrations close to $2 \mathrm{ng} \mathrm{g}^{-1}$ d.w. COC, OXCBZ, and OH-DCF were not detected in any sample, whereas SMX was found at levels below its MLQ. Overall, this preliminary data set indicates that the selected pharmaceuticals may effectively accumulate in soils. They may even reach measurable concentrations in reclaimed water-irrigated soil.

\section{Conclusions}

This study presents a simple and effective procedure to determine the presence of selected drugs in soil samples. The method developed allows the extraction of analytes with different physical-chemical properties and therefore, it could potentially be applied to the extraction of pharmaceutically active compounds with similar structures, or belonging to the same chemical classes. The analytical method described enables the detection and quantification of the selected compounds in soil samples in the low $\mathrm{ng} \mathrm{g}^{-1} \mathrm{~d}$.w. range, which is the concentration level at which this type of compounds is expected to occur in the environment. The proposed method showed good performance in terms of linearity, accuracy, and precision and provides reliable results due to the use of isotopically labeled compounds as surrogate standards that contribute to correct for potential extraction losses and matrix effects.

Application of the developed methodology to potting soil samples exposed to the target analytes through irrigation with artificial water and wastewater treatment plant effluent for 60 days suggested the potential accumulation of all investigated drugs in soil. Future work will be directed to study these compounds in the water-soil-plant system, to evaluate the potential effects that wastewater reuse in agriculture could have on the environment and eventually on human health.

Acknowledgments The authors thank the Water Challenges for a Changing World Joint Programming Initiative, and the Spanish Ministry of Economy, Industry and Competitiveness (MINECO). The $\mathrm{EU}$ is not liable for any use that may be made of the information contained therein.

Funding information This study has been financially supported by the EU through the WaterJPI-2015 AWARE project (PCIN-2017-067) and the Generalitat de Catalunya (Consolidated Research Group "2017 SGR 01404 - Water and Soil Quality Unit”).

\section{Compliance with ethical standards}

Conflict of interest The authors declare that there are no conflicts of interest.

Publisher's note Springer Nature remains neutral with regard to jurisdictional claims in published maps and institutional affiliations.

\section{References}

1. Vodyanitskii YN, Yakovlev A. Contamination of soils and groundwater with new organic micropollutants: a review. Eurasian Soil Sci. 2016;49(5):560-9.

2. Ferhi S, Bourdat-Deschamps M, Daudin J-J, Houot S, Nélieu S. Factors influencing the extraction of pharmaceuticals from sewage sludge and soil: an experimental design approach. Anal Bioanal Chem. 2016;408(22):6153-68.

3. Petrie B, Barden R, Kasprzyk-Hordern B. A review on emerging contaminants in wastewaters and the environment: current knowledge, understudied areas and recommendations for future monitoring. Water Res. 2015;72:3-27.

4. Carter LJ, Garman CD, Ryan J, Dowle A, Bergström E, ThomasOates J, et al. Fate and uptake of pharmaceuticals in soil-earthworm systems. Environ Sci Technol. 2014;48(10):5955-63. 
Li WC. Occurrence, sources, and fate of pharmaceuticals in aquatic environment and soil. Environ Pollut. 2014;187:193-201.

Monteiro SC, Boxall AB. Occurrence and fate of human pharmaceuticals in the environment. Rev Environ Contam Toxicol. Springer; 2010. p. 53-154.

Zhao L, Dong YH, Wang H. Residues of veterinary antibiotics in manures from feedlot livestock in eight provinces of China. Sci Total Environ. 2010;408(5):1069-75.

Durán-Alvarez JC, Becerril-Bravo E, Castro VS, Jiménez B, Gibson R. The analysis of a group of acidic pharmaceuticals, carbamazepine, and potential endocrine disrupting compounds in wastewater irrigated soils by gas chromatography-mass spectrometry. Talanta. 2009;78(3):1159-66.

Kümmerer $\mathrm{K}$. The presence of pharmaceuticals in the environment due to human use-present knowledge and future challenges. J Environ Manag. 2009;90(8):2354-66.

Redshaw CH, Cooke MP, Talbot HM, McGrath S, Rowland SJ. Low biodegradability of fluoxetine $\mathrm{HCl}$, diazepam and their human metabolites in sewage sludge-amended soil. J Soils Sediments. 2008;8(4):217.

Aga DS. Fate of pharmaceuticals in the environment and in water treatment systems. CRC Press; 2007.

Kinney CA, Furlong ET, Zaugg SD, Burkhardt MR, Werner SL, Cahill JD, et al. Survey of organic wastewater contaminants in biosolids destined for land application. Environ Sci Technol. 2006;40(23):7207-15.

Jjemba PK. Excretion and ecotoxicity of pharmaceutical and personal care products in the environment. Ecotoxicol Environ Saf. 2006;63(1):113-30.

Boxall AB, Sinclair CJ, Fenner K, Kolpin D, Maund SJ. Peer reviewed: when synthetic chemicals degrade in the environment. ACS Publications; 2004

Kuster M, de Alda MJL, Barcelo D. Analysis and distribution of estrogens and progestogens in sewage sludge, soils and sediments. TrAC Trends Anal Chem. 2004;23(10-11):790-8.

Golet EM, Xifra I, Siegrist H, Alder AC, Giger W. Environmental exposure assessment of fluoroquinolone antibacterial agents from sewage to soil. Environ Sci Technol. 2003;37(15):3243-9.

Kumar K, Gupta SC, Chander Y, Singh AK. Antibiotic use in agriculture and its impact on the terrestrial environment. Adv Agron. 2005;87:1-54

Sallach JB, Zhang Y, Hodges L, Snow D, Li X, Bartelt-Hunt S. Concomitant uptake of antimicrobials and Salmonella in soil and into lettuce following wastewater irrigation. Environ Pollut. 2015; 197:269-77.

Resistance WA. Fact sheet N 194. Updated April. 2015.

Meyer E, Gastmeier P, Deja M, Schwab F. Antibiotic consumption and resistance: data from Europe and Germany. Int J Med Microbiol. 2013;303(6-7):388-95.

Montemurro N, Postigo C, Lonigro A, Perez S, Barceló D. Development and validation of an analytical method based on liquid chromatography-tandem mass spectrometry detection for the simultaneous determination of 13 relevant wastewater-derived contaminants in lettuce. Anal Bioanal Chem. 2017;409(23):5375-87. Prosser R, Sibley P. Human health risk assessment of pharmaceuticals and personal care products in plant tissue due to biosolids and manure amendments, and wastewater irrigation. Environ Int. 2015;75:223-33.

Carter LJ, Harris E, Williams M, Ryan JJ, Kookana RS, Boxall AB. Fate and uptake of pharmaceuticals in soil-plant systems. J Agric Food Chem. 2014;62(4):816-25.

Wu C, Spongberg AL, Witter JD, Sridhar BM. Transfer of wastewater associated pharmaceuticals and personal care products to crop plants from biosolids treated soil. Ecotoxicol Environ Saf. 2012;85:104-9.
Shenker M, Harush D, Ben-Ari J, Chefetz B. Uptake of carbamazepine by cucumber plants-a case study related to irrigation with reclaimed wastewater. Chemosphere. 2011;82(6):905-10.

Dolliver H, Kumar K, Gupta S. Sulfamethazine uptake by plants from manure-amended soil. J Environ Qual. 2007;36(4):1224-30. Boxall AB, Johnson P, Smith EJ, Sinclair CJ, Stutt E, Levy LS. Uptake of veterinary medicines from soils into plants. J Agric Food Chem. 2006;54(6):2288-97.

Picó Y, Alvarez-Ruiz R, Alfarhan AH, El-Sheikh MA, Alobaid SM, Barceló D. Uptake and accumulation of emerging contaminants in soil and plant treated with wastewater under real-world environmental conditions in the Al Hayer area (Saudi Arabia). Sci Total Environ. 2019;652:562-72.

Łukaszewicz P, Białk-Bielińska A, Dołżonek J, Kumirska J, Caban M, Stepnowski P. A new approach for the extraction of tetracyclines from soil matrices: application of the microwave-extraction technique. Analy Bioanal Chem. 2018;1-11.

Azzouz A, Ballesteros E. Combined microwave-assisted extraction and continuous solid-phase extraction prior to gas chromatography-mass spectrometry determination of pharmaceuticals, personal care products and hormones in soils, sediments and sludge. Sci Total Environ. 2012;419:208-15.

Biel-Maeso M, Corada-Fernández C, Lara-Martín PA. Determining the distribution of pharmaceutically active compounds (PhACs) in soils and sediments by pressurized hot water extraction (PHWE). Chemosphere. 2017;185:1001-10.

Vazquez-Roig P, Segarra R, Blasco C, Andreu V, Picó Y. Determination of pharmaceuticals in soils and sediments by pressurized liquid extraction and liquid chromatography tandem mass spectrometry. J Chromatogr A. 2010;1217(16):2471-83.

Barron L, Tobin J, Paull B. Multi-residue determination of pharmaceuticals in sludge and sludge enriched soils using pressurized liquid extraction, solid phase extraction and liquid chromatography with tandem mass spectrometry. J Environ Monit. 2008;10(3): 353-61.

Jelić A, Petrović M, Barceló D. Multi-residue method for trace level determination of pharmaceuticals in solid samples using pressurized liquid extraction followed by liquid chromatography/ quadrupole-linear ion trap mass spectrometry. Talanta. 2009;80(1):363-71

Bragança I, Plácido A, Paíga P, Domingues VF, Delerue-Matos C. QuEChERS: a new sample preparation approach for the determination of ibuprofen and its metabolites in soils. Sci Total Environ. 2012;433:281-9.

De Carlo RM, Rivoira L, Ciofi L, Ancillotti C, Checchini L, Del Bubba M, et al. Evaluation of different QuEChERS procedures for the recovery of selected drugs and herbicides from soil using LC coupled with UV and pulsed amperometry for their detection. Anal Bioanal Chem. 2015;407(4):1217-29.

Albero B, Sánchez-Brunete C, García-Valcárcel AI, Pérez RA, Tadeo JL. Ultrasound-assisted extraction of emerging contaminants from environmental samples. TrAC Trends Anal Chem. 2015;71: $110-8$.

Pico Y. Ultrasound-assisted extraction for food and environmental samples. TrAC Trends Anal Chem. 2013;43:84-99.

Hao C, Zhao X, Yang P. GC-MS and HPLC-MS analysis of bioactive pharmaceuticals and personal-care products in environmental matrices. TrAC Trends Anal Chem. 2007;26(6):569-80.

Nödler K, Hillebrand O, Idzik K, Strathmann M, Schiperski F, Zirlewagen J, et al. Occurrence and fate of the angiotensin II receptor antagonist transformation product valsartan acid in the water cycle-a comparative study with selected $\beta$-blockers and the persistent anthropogenic wastewater indicators carbamazepine and acesulfame. Water Res. 2013;47(17):6650-9. 
Analysis and fate of 14 relevant wastewater-derived organic pollutants in long-term exposed soil

41. Italian official methods of soil chemical analysis, Italian official methods of soil chemical analysis. Gazzetta Ufficiale della Repubblica Italiana SoN, 21/10/1999.

42. Matuszewski B, Constanzer M, Chavez-Eng C. Strategies for the assessment of matrix effect in quantitative bioanalytical methods based on HPLC-MS/MS. Anal Chem. 2003;75(13):3019-30.

43. Bruzzoniti MC, Checchini L, De Carlo RM, Orlandini S, Rivoira L, Del Bubba M. QuEChERS sample preparation for the determination of pesticides and other organic residues in environmental matrices: a critical review. Anal Bioanal Chem. 2014;406(17):4089116.

44. Berlioz-Barbier A, Vauchez A, Wiest L, Baudot R, Vulliet E, CrenOlivé C. Multi-residue analysis of emerging pollutants in sediment using QuEChERS-based extraction followed by LC-MS/MS analysis. Anal Bioanal Chem. 2014;406(4):1259-66.

45. Golovko O, Koba O, Kodesova R, Fedorova G, Kumar V, Grabic R. Development of fast and robust multiresidual LC-MS/MS method for determination of pharmaceuticals in soils. Environ Sci Pollut Res. 2016;23(14):14068-77.
46. Wu C, Spongberg AL, Witter JD, Fang M, Ames A, Czajkowski KP. Detection of pharmaceuticals and personal care products in agricultural soils receiving biosolids application. CLEAN-Soil, Air, Water. 2010;38(3):230-7.

47. Handreck KA, Black ND. Growing media for ornamental plants and turf. UNSW press; 2002.

48. Bunt B. Media and mixes for container-grown plants: a manual on the preparation and use of growing media for pot plants. Springer Science \& Business Media; 2012.

49. Antignac J-P, Le Bizec B, Monteau F, Andre F. Validation of analytical methods based on mass spectrometric detection according to the "2002/657/EC" European decision: guideline and application. Anal Chim Acta. 2003;483(1-2):325-34. 


\section{AUTHOR'S PROOF!}

\section{AUTHOR QUERIES}

\section{AUTHOR PLEASE ANSWER ALL QUERIES.}

Q1. Please check if the affiliations are presented correctly.

Q2. Figures $2 \&$ graphical abstract contains poor quality and small text inside the artwork. Please do not re-use the file that we have rejected or attempt to increase its resolution and re-save. It is originally poor, therefore, increasing the resolution will not solve the quality problem. We suggest that you provide us the original format. We prefer replacement figures containing vector/editable objects rather than embedded images. Preferred file formats are eps, ai, tiff and pdf. 